\title{
PROBLEMÁTICA NO USO DA TERRA E NO MANEJO AGRÍCOLA DA BATATICULTURA EM BUENO BRANDÃO, MG
}

\section{Problematic in land use and management of agricultural production of potatoes in Bueno Brandão, MG (Brazil)}

Vassiliki Terezinha Galvão Boulomytis

Doutoranda em Sensoriamento Remoto pelo INPE. Bolsista CAPES Docente no Depto. de Construção Civil, IFSP, Campus Caraguatatuba, likitgb@yahoo.com

Ruben Bresaola Junior Prof. Titular, Depto. de Saneamento e Meio Ambiente, FEC, UNICAMP bresaola@fec.unicamp.br

Artigo recebido em 31/05/2011 e aceito para publicação em 04/03/2013

RESUMO A batata é um alimento que possui elevado valor biológico e importância social significativa no combate à fome. O seu manejo usa tradicionalmente a mecanização agrícola antes e durante o cultivo, água abundante em áreas bem drenadas e agroquímicos para a fertilização do solo e combate às pragas. Por muitas décadas o plantio de batatas tem se destacado como uma das atividades sócio-econômicas mais importantes do município de Bueno Brandão, sul do estado de Minas Gerais. Neste trabalho, foi realizado o monitoramento das áreas destinadas à bataticultura na área drenada pela sub-bacia do Rio das Antas, a fim de obter um pré-diagnóstico do manejo agrícola adotado na região e dos impactos decorrentes do uso intensivo de produtos agroquímicos, da proximidade do plantio aos cursos d'água e da mecanização agrícola em áreas com declividades acentuadas. Foi verificada a predominância do sistema semi-mecanizado, que desconsidera o relevo acidentado. Averiguou-se também que na maioria dos casos a análise do solo ou a consultoria de agrônomos deixam de ser realizadas como subsídio ao tratamento do solo e do plantio. Portanto, concluiu-se que o sistema de produção utilizado não está em concordância com a fragilidade ambiental da região, que é montanhosa e repleta de cursos d'água, tornando-a muito susceptível à erosão e contaminação hídrica.

Palavras-chave: Agroquímicos, área de preservação permanente, mecanização, erosão, contaminação.

ABSTRACT The potato is a food which has a high biological value and significant social importance in the fight against hunger. Its management traditionally uses mechanization before and during cultivation, plenty of water in well-drained soils and agrochemicals for soil fertilization and pest control. For many decades, the potato cropping has emerged as one of the most remarkable social-economic activities of the city of Bueno Brandão, in the southern part of Minas Gerais State. In this work, the potato cropping areas in the sub-basin of Rio das Antas were monitored in order to obtain a pre-diagnosis of the agricultural management adopted in the region and the environmental impacts due to the intensive use of agrochemicals, proximity to water courses and mechanization in steep slopes areas. It was possible to verify the predominance of the semi-mechanized system which disregards the terrain slopes. It was also found that in most cases the soil analysis or consulting agronomists cease to be performed for soil treatment and planting. Therefore, it was concluded that the production system used is not according to the environmental fragility of the region, which is mountainous and full of waterways, making it very susceptible to erosion and water contamination.

Keywords: Agrochemicals, permanent preservation area, mechanization, erosion, and contamination. 


\section{INTRODUÇÃO}

A batata é uma das culturas mais consumidas mundialmente e representa um papel muito importante na nutrição humana. $\mathrm{O}$ consumo médio anual é de aproximadamente $32 \mathrm{~kg}$ por pessoa (KATO, 2008). A Organização das Nações Unidas (ONU) estabeleceu 2008 como o "Ano Internacional da Batata”, de modo a promover a importância da cultura ao combate mundial à fome e à pobreza, além de salientar o risco ambiental devido ao manejo inadequado de seu cultivo.

$\mathrm{O}$ valor biológico de um alimento indica o percentual do alimento digerido utilizado pelo corpo humano. Melo (2008) afirma que a batata é o terceiro alimento com maior valor biológico, atrás somente do ovo e do leite. Por isso, pode ser considerado como um alimento muito importante para o combate à fome, principalmente se a produção em grande escala for sustentável e ocorrer de modo integrado.

O sistema de produção integrada da batata, além de econômico, visa atender a qualidade final do produto, priorizando a utilização de um manejo adequado e o emprego racional dos agroquímicos, de modo a minimizar o impacto ambiental e a melhorar a qualidade da saúde humana. Assim, o objetivo geral do sistema é de elevar os padrões de qualidade e com- petitividade da batata, através do manejo sustentável da produção agrícola.

Segundo Young (2008), o uso de tecnologias limpas possibilita reverter o custo em benefício, através de ganhos no rendimento e na produtividade. Portanto, o sistema de produção integrada da batata, poderia se relacionar à situação denominada win-win, no qual o ganho de competitividade ocorre concomitantemente com o ganho social. Isso só é possível através do ganho ambiental porque, não se pode conceber a falta de análise ou responsabilidade em relação aos impactos causados sobre as pessoas atingidas por um novo empreendimento direta ou indiretamente (BRUNS, 2008). Na bataticultura o novo empreendimento poderia ser considerado como um novo local de plantio que, através do manejo inadequado na produção agrícola, torna possível a contaminação ou destruição dos recursos naturais, podendo afetar toda uma população.

No sistema integrado de plantio, verifica-se uma menor possibilidade de impacto ambiental, considerando-se a adoção de práticas conservacionistas, o uso controlado de agroquímicos, o plantio de sementes certificadas e o monitoramento de doenças e pragas (Quadro 1).

Quadro 1: Diferença entre os diferentes sistemas empregados na produção de batata.

\begin{tabular}{|l|l|l|l|}
\hline Prática Adotada & \multicolumn{1}{|c|}{ Sistema Convencional } & \multicolumn{1}{|c|}{ Sistema Orgânico } & \multicolumn{1}{|c|}{ Sistema Integrado } \\
\hline Manejo do Solo & $\begin{array}{l}\text { Uso intensivo de máqui- } \\
\text { nas agrícolas. Ausência } \\
\text { de práticas conservacio- } \\
\text { nistas. }\end{array}$ & $\begin{array}{l}\text { Em concordância com a entidade } \\
\text { ertificadora. Utilização de prá- } \\
\text { ticas conservacionistas e rotação } \\
\text { de culturas recomendadas. }\end{array}$ & $\begin{array}{l}\text { Preparação mínima do } \\
\text { solo. Práticas conservacio- } \\
\text { nistas e rotação de culturas. }\end{array}$ \\
\hline $\begin{array}{l}\text { Produtos Fitos- } \\
\text { sanitários }\end{array}$ & Uso intensivo. & $\begin{array}{l}\text { Produtos naturais ou alternativos. } \\
\text { Monitoramento de doenças e pragas. }\end{array}$ & $\begin{array}{l}\text { Uso controlado. Monitora- } \\
\text { mento de doenças e pragas. }\end{array}$ \\
\hline Fertilização & $\begin{array}{l}\text { Uso de fertilizantes } \\
\text { utilizando-se ou não a } \\
\text { análise do solo e das } \\
\text { folhas. }\end{array}$ & $\begin{array}{l}\text { Uso somente de produtos orgânicos. } \\
\text { Batata-semente orgânica baseada no } \\
\text { resultado de análise do solo } \\
\text { e das folhas. }\end{array}$ \\
\hline $\begin{array}{l}\text { De acordo com a legis- } \\
\text { lação do Ministério de } \\
\text { Agricultura, Pecuária e } \\
\text { Abastecimento (MAPA) }\end{array}$ & $\begin{array}{l}\text { A critério das entidades } \\
\text { ertificadoras. }\end{array}$ & $\begin{array}{l}\text { O uso de batata certificada } \\
\text { é obrigatório. }\end{array}$ \\
\hline
\end{tabular}

Fonte: Centro de Inteligência da Batata (CIB), 2008 (adaptado). 
No contexto social, a batata pode ser a principal responsável pela geração de renda da comunidade envolvida no processo, desde a produção das sementes até o beneficiamento do alimento após a sua colheita. Segundo Rocha (2007), somente no sul de Minas Gerais, a bataticultura oferece, aproximadamente, 120 mil empregos diretos e indiretos. Muitas vezes, em pequenos municípios, a vida socioeconômica da população depende exclusivamente da bataticultura. Deste modo, quando a safra da batata tem um resultado negativo no mercado, ocorre recessão em todos os setores (SILVA, 2008).

No entanto, como em todos os meios produtivos, as práticas agrícolas podem causar impactos significativos ao ambiente de plantio e à sua área de influência, dependendo de como ocorre o manejo agrícola. Deste modo, é importante conhecer o histórico de ocupação da área e a sua relação com as características físicas, os impactos ambientais e os aspectos socioeconômicos da região (LIMA E VALARINI, 1996).

Como acontece com diversas culturas, durante a etapa de pré-plantio da batata, o local torna-se desprovido de vegetação, contendo um solo desagregado. Por isso, há maior suscetibilidade à erosão nas camadas superficiais, nas quais são utilizados os produtos agroquímicos, para a correção do solo, prevenção e combate a pragas.

Desde a pré-história, o homem pratica a agricultura convivendo com problemas relacionados às pragas e doenças que destroem as suas colheitas. Há cerca de mil anos atrás, os chineses já utilizavam compostos de arsênio para combater tais problemas e assegurar o seu sustento (CARRARO, 1997). Deste modo, a utilização de agroquímicos não deve ser ignorada ou impugnada pela sociedade, mas sim, questionada, se de fato é necessária para o local em que se pretende praticá-la, se o seu manejo e uso são adequados e se não pode ser substituída ou complementada por medidas conservacionistas.

A mobilidade dos agroquímicos pode ocorrer no solo ou através do deslocamento das massas de are águas de chuva para locais distantes das áreas de plantio. Por isso, deve-se conhecer tanto a sua tipologia, como a sua mobilidade no compartimento ambiental a ser estudado.

Os fertilizantes representam o conjunto de nutrientes que devem ser introduzidos para suprir a deficiência de alguns elementos no solo, necessários para o desenvolvimento natural de uma determinada cultura. Se aplicados de modo inadequado, podem ser depositados nos sedimentos dos cursos d'água ou nas partes mais baixas do relevo, em função da erosão que ocorre nas partes mais altas e do respectivo assoreamento nas regiões mais baixas, ou seja, após o escoamento superficial das águas sobre as áreas de plantio (MESQUITA et al., 1999). Logo, se a aplicação é feita em larga escala, e não há tempo suficiente para que o mineral seja fixado às partículas do solo ou raízes das plantas, as águas das chuvas transportam os sedimentos que o compõem para os cursos d'água, principalmente se estes não contarem com a proteção de mata ciliar.

Segundo Yost et al. (1981) nas situações em que ocorre uma elevada capacidade de retenção de fósforo pelo solo e quando o manejo dos fertilizantes fosfatados é adequado, o nutriente é disponibilizado para as plantas por uma série de sucessivos cultivos. No entanto, o emprego indiscriminado de fósforo e nitrogênio vem ocasionando relevante preocupação nos efeitos nocivos que o mesmo pode representar à qualidade das águas subterrâneas e superficiais, e consequentemente, à saúde humana.

$\mathrm{O}$ fósforo é um elemento essencial para a constituição de Trifosfato de Adenosina (ATP), Ácido Desoxirribonucléico (DNA) e Ácido Ribonucléico (RNA). Berton (1994) relata que, devido à baixa mobilidade do fósforo no solo, ele representa pouca ameaça às águas subterrâneas, mas grande risco às águas superficiais. Neste caso a sua perda ocorre por escoamento superficial, podendo ocasionar a eutrofização dos cursos d'água. Quando o fósforo é ingerido pelos seres vivos em doses elevadas, pode ocasionar a redução na absorção de ferro e zinco pelo organismo (LUDOVICE, 2003).

De acordo com Brigante et al. (2003a) em pesquisa realizada na nascente do Rio Mogi-Guaçu, em Bom Repouso, MG, foi verificada a concentração de fosfato inorgânico e total, a duas ou três vezes superior à concentração presente nas demais nascentes, devido aos prováveis efeitos da agricultura e da ausência de práticas conservacionistas no solo da área de entorno da nascente. 
O nitrogênio possui um dos ciclos biogeoquímicos mais complexos da natureza. A sua importância aos seres vivos se deve à responsabilidade pela constituição de proteínas e ácidos nucléicos. Entretanto, este elemento somente pode ser utilizado pelas plantas na forma reativa e não como composto inerte. Portanto, é necessária a ligação de nitrogênio às moléculas de hidrogênio, carbono ou oxigênio, a qual depende da atuação das bactérias fixadoras de nitrogênio, presentes nas raízes de plantas do tipo leguminosas. Como os nitratos não se dissolvem facilmente em argilas, o excesso de nitrogênio tende a permanecer no sistema na forma de nitrato, podendo causar a contaminação dos cursos d'água, por escoamento superficial, ou das águas subterrâneas, por lixiviação.

Segundo Alaburda e Nishihara (1998), o nitrato é geralmente encontrado em baixos teores nas águas superficiais, podendo atingir maiores concentrações em águas profundas. Nas águas de abastecimento, o seu consumo pode induzir a metemoglobinemia, principalmente nas crianças menores de 3 meses de idade ou adultos com gastroenterites, anemia, porções do estomago removidas cirurgicamente e mulheres grávidas, além de formar nitrosaminas e nitrosamidas carcinogênicas. Por outro lado, o nitrito pode induzir a metemoglobinemia às pessoas que o ingerirem diretamente, independente de sua idade.

Costa (2001) afirma que as plantas fazem o aproveitamento de potássio, através da absorção do mesmo pelas suas raízes. A movimentação do nutriente ocorre através do deslocamento do íon em solução aquosa, a favor de um gradiente de concentração, ou seja, de uma região de maior para uma de menor concentração. Deste modo, no caso de uma aplicação inadequada de adubação potássica, ou em terrenos compostos por solo do tipo arenoso, deve ocorrer lixiviação e possível, contaminação das águas subterrâneas.

Quanto aos agrotóxicos utilizados na agricultura, a mudança da terminologia de Defensivo Agrícola para Agrotóxico, foi feita após grande mobilização da sociedade civil brasileira organizada, a fim de evidenciar a toxicidade desses produtos ao meio ambiente e à saúde humana. Estes agroquímicos também são popularmente chamados de praguicidas ou pesticidas, devido à sua função principal de con- trolar insetos, pragas e plantas daninhas de culturas na fase de preparo do solo, plantio, armazenamento e distribuição (PORTAL FARMÁCIA, 2008). De acordo com a Lei Federal n ${ }^{\circ} 7.802$ de 11/07/89, a sua definição é expressa como:

Agrotóxicos são os produtos e os componentes de processos físicos, químicos ou biológicos destinados ao uso nos setores de produção, armazenamento e beneficiamento de produtos agrícolas, nas pastagens, na proteção de florestas nativas ou implantadas e de outros ecossistemas e também em ambientes urbanos, hidricos e industriais, cuja finalidade seja alterar a composição da flora e da fauna, a fim de preservá-la da ação danosa de seres vivos considerados nocivos, bem como substâncias e produtos empregados como desfolhantes, dessecantes, estimuladores e inibidores do crescimento.

Os agrotóxicos são compostos por princípios ativos, com ingredientes inertes e aditivos usados na sua fabricação e são classificados em função do grupo químico aos quais os mesmos pertencem e da sua toxicidade (BRASIL, 1989).

De acordo com Peres e Moreira (2007), a exposição aos agrotóxicos pode causar efeitos agudos e crônicos ao ser humano, como: dificuldade respiratória, lesões renais e hepáticas, Mal de Parkinson, cânceres, entre outras mais.

Segundo Brigante et al. (2003b) os organofosforados, apesar de menor permanência no meio ambiente, podem ocasionar um efeito extremamente tóxico, pois são inibidores de acetilcolinesterase e seu acúmulo no ser humano pode ser fatal, tanto devido à exposição a baixos níveis de modo contínuo, quanto devido à intoxicação aguda.

No que diz respeito às características químicas do solo, Filgueira (1999) afirma que a fertilidade do solo pode ser melhorada através da implantação das inúmeras técnicas agronômicas disponíveis. Entretanto, para que as operações possam ser mecanizadas, $o$ terreno deve apresentar topografia plana ou com baixa declividade. Em terrenos muito acidentados, além do custo para o plantio ser mais elevado, há maior risco à erosão e complexidade nas operações. 
Assim, o modo de plantio da batata deve ser coerente com o tipo de relevo do local. Em locais planos o sistema pode ser mecanizado. Já se o local possuir relevo acidentado, o plantio deve ser manual, podendo alguns dos procedimentos a serem adotados do tipo semi-mecanizados.
Os sistemas adotados nas duas regiões mais produtivas de batatas de MG, Alto Paranaíba/Triângulo Mineiro e Sul de Minas, são completamente distintos, em decorrência das diferentes condições de relevo e do clima (Tabela 1).

Tabela 1: Sistemas produtivos aplicados na bataticultura do Alto Paranaíba/Triângulo Mineiro e do Sul de MG.

\begin{tabular}{|c|c|c|c|}
\hline \multicolumn{2}{|r|}{ Região } & $\begin{array}{c}\text { Municípios do } \\
\text { Alto Paranaíba/Triângulo Mineiro }\end{array}$ & \begin{tabular}{|c|} 
Municípios do \\
Sul de Minas \\
\end{tabular} \\
\hline \multicolumn{2}{|l|}{ Área Colhida em 2007} & 16.259 ha & 22.230 ha \\
\hline \multicolumn{2}{|l|}{ Produção em 2007} & $501.565 \mathrm{t}$ & $575.080 \mathrm{t}$ \\
\hline \multicolumn{2}{|c|}{ Produtividade em 2007} & $30,85 \mathrm{t} / \mathrm{ha}$ & $25,87 \mathrm{t} / \mathrm{ha}$ \\
\hline \multirow{3}{*}{ Preparo do Solo } & mecanizado & $100 \%$ & $56 \%$ \\
\hline & manual & - & $31 \%$ \\
\hline & semi-mecanizado com manual & - & $13 \%$ \\
\hline \multirow{5}{*}{ Plantio da Cultura } & mecanizado & $78 \%$ & $6 \%$ \\
\hline & manual & - & $75 \%$ \\
\hline & semi-mecanizado & - & $13 \%$ \\
\hline & semi-mecanizado com mecanizado & $22 \%$ & - \\
\hline & semi-mecanizado com manual & - & $6 \%$ \\
\hline \multirow{4}{*}{ Tratos Culturais } & mecanizado & $100 \%$ & $13 \%$ \\
\hline & manual & - & $38 \%$ \\
\hline & semi-mecanizado com mecanizado & - & $12 \%$ \\
\hline & semi-mecanizado com manual & - & $37 \%$ \\
\hline \multirow{6}{*}{ Colheita } & mecanizado & $11 \%$ & - \\
\hline & manual & - & $19 \%$ \\
\hline & semi-mecanizado & $66 \%$ & $19 \%$ \\
\hline & semi-mecanizado com mecanizado & $23 \%$ & - \\
\hline & semi-mecanizado com manual & - & $50 \%$ \\
\hline & mecanizado com manual & - & $12 \%$ \\
\hline \multirow{11}{*}{ Sistema de Irrigação } & \multirow{2}{*}{\begin{tabular}{|l|l|} 
& aspersão convencional \\
$1^{\mathrm{a}}$ safra & não irrigam \\
\cline { 2 - 2 }
\end{tabular}} & $33 \%$ & $94 \%$ \\
\hline & & $67 \%$ & - \\
\hline & não plantam & - & $6 \%$ \\
\hline & aspersão convencional & $23 \%$ & $88 \%$ \\
\hline & $\begin{array}{l}\text { aspersão convencional com } \\
2^{\mathrm{a}} \text { safra pivô central }\end{array}$ & $55 \%$ & - \\
\hline & não irrigam & $22 \%$ & - \\
\hline & não plantam & - & $12 \%$ \\
\hline & aspersão convencional & - & $75 \%$ \\
\hline & $\begin{array}{l}\text { aspersão convencional com } \\
3^{\mathrm{a}} \text { safra pivô central }\end{array}$ & $56 \%$ & - \\
\hline & pivô central & $44 \%$ & - \\
\hline & não plantam & - & $25 \%$ \\
\hline
\end{tabular}


Na região do Alto Paranaíba/Triângulo Mineiro, verifica-se que o uso de roçadeiras em $78 \%$ dos municípios não se alterou, mas o uso de outras máquinas agrícolas aumentou em 33\% nos últimos anos. No Sul de Minas, o uso de tratores aumentou em $69 \%$, enquanto o de roçadeiras se manteve estável, e o de outras máquinas aumentou $44 \%$. Este fato mostra que os produtores têm investido na compra de equipamentos, embora o uso dos mesmos não seja adequado em muitos locais, devido ao relevo acidentado característico na região.

No Brasil, Minas Gerais é o maior produtor de batatas com o total de $31,6 \%$ da produção (IBGE, 2012). De 2001 a 2005, a mesorregião sul de $M G$ ocupou o $1^{\circ}$ lugar na produção estadual, com mais de $50 \%$ do total. Já na microrregião de Pouso Alegre,sul de MG, o município de Bueno Brandão tem ocupado a $5^{\circ}$ posição na produção de batatas.

O município de Bueno Brandão apresenta características propícias de fertilidade natural do solo e abundância de recursos hídricos disponíveis para o plantio de batatas. Isso porque o plantio da batata deve ser feito em local ensolarado, com temperatura amena, e muita água disponível para a irrigação. Além disso, o terreno deve apresentar boas características de aeração, baixa compacidade e facilidade de drenagem, pois a planta não tolera encharcamento.

Apesar do desenvolvimento histórico da bataticultura em Bueno Brandão, medidas conservacionistas são pouco empregadas e a ocorrência de desmatamento nas margens dos cursos d'água é predominante na região de relevo tipicamente acidentado. Ainda assim, há poucos estudos desenvolvidos sobre o local para monitorar os sistemas de plantio e impactos associados. Deste modo, o objetivo deste trabalho foi de monitorar o manejo da bataticultura nas propriedades que se encontravam em áreas de preservação permanente (APP) e no seu entorno a fim de traçar um pré-diagnóstico do manejo agrícola empregado na região. Em cada uma das propriedades foram levantadas informações referentes à quantidade de agroquímicos utilizados e às amostragens do solo, se haviam sido analisadas em laboratórios (para a verificação das quantidades de nutrientes que a terra necessitaria para a produção). Além disso, também foi verificado o sistema de produção utilizado, manual ou mecanizado, e se era coerente com as condições de relevo do local. A justificativa deste trabalho advém da integração dos dados obtidos, através da qual torna-se possível verificar o manejo da bataticultura e a susceptibilidade da área de estudo à erosão e contaminação das águas superficiais.

\section{MATERIAIS E MÉTODOS}

A pesquisa foi realizada no município de Bueno Brandão, que está localizado na região sul de Minas Gerais, Microrregião da Alta Mantiqueira e do Médio Sapucaí. A altitude máxima do local é de 1.719 m e a mínima de $840 \mathrm{~m}$ na latitude S $22^{\circ} 26^{\prime} 27^{\prime \prime}$ e longitude W $46^{\circ} 21^{\prime} 03^{\prime \prime}$.

A área total do município é de $355,23 \mathrm{~km}^{2} \mathrm{e}$ compreende toda a sub-bacia do Rio das Antas, localizada à montante da captação d'água para abastecimento público, o que motivou o estudo nesta região.

A área total da sub-bacia é de $50,22 \mathrm{~km}^{2}$, entre as latitudes S $22^{\circ} 31^{\prime} 38^{\prime \prime}$ e S $22^{\circ} 24^{\prime} 17^{\prime \prime}$ e longitudes W 46 $22^{\circ} 13^{\prime \prime}$ e W $46^{\circ} 13^{\prime} 56^{\prime}$ ", do sistema geodésico de referência Córrego Alegre. Ela se estende até a divisa com os municípios de Senador Amaral e Bom Repouso, com toda a água de abastecimento da área urbana passando integralmente pelos bairros de Campo Grande, Esmeril, Mergulho, Ressaca e Santana, e parcialmente pelos bairros Dois Irmãos, Santa Rita, Torre e Vargem Grande. Nestes bairros, a maioria dos agricultores dedica-se à bataticultura (Figura 1). 


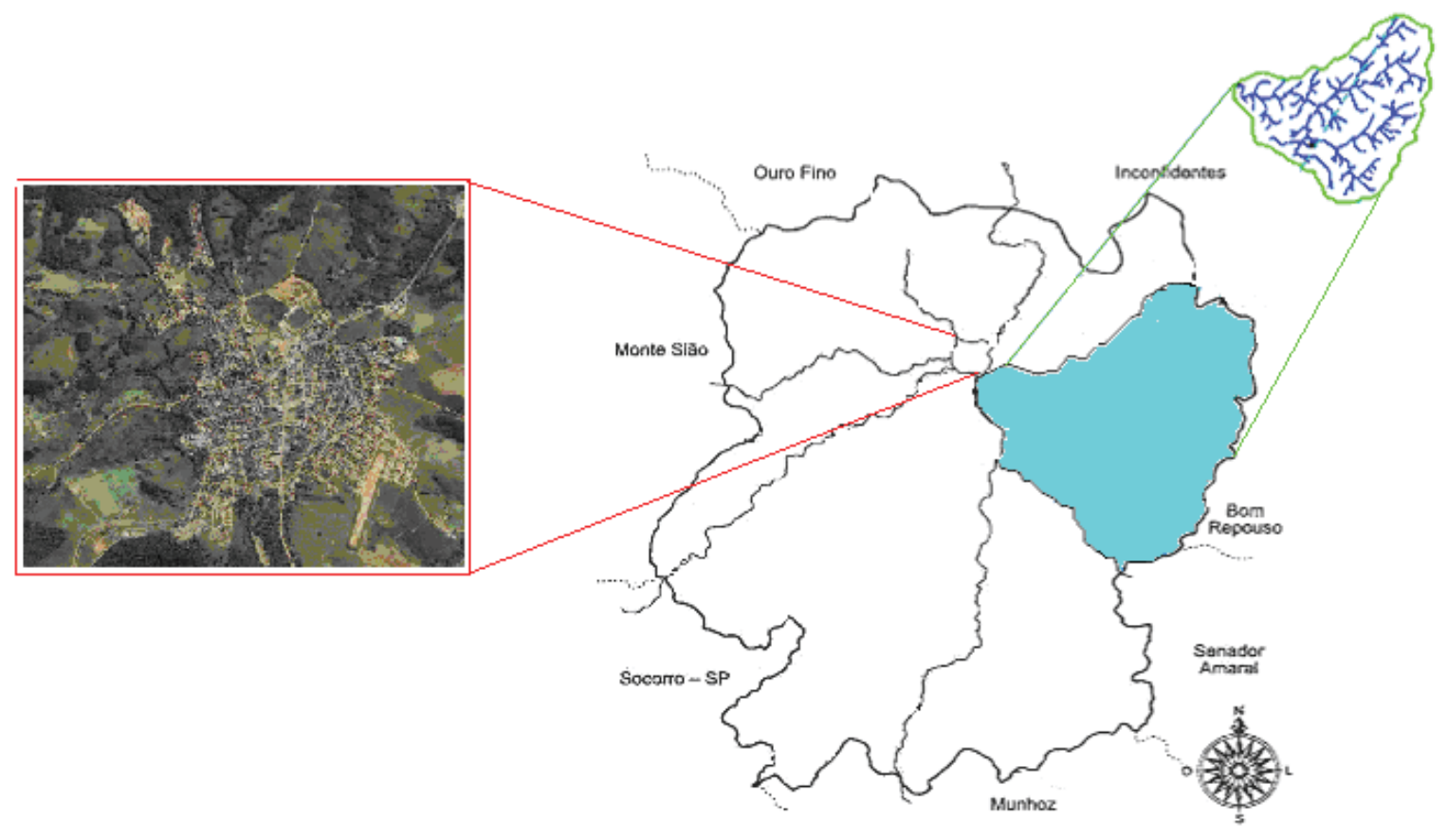

Fonte: Adaptado de Brigante et al. (2003a).

Segundo o Sistema Internacional de Köepen o clima da região é identificado como Cwb, ou seja, do tipo mesotérmico e caracterizado por verões brandos e úmidos. A temperatura média anual é de $17^{\circ} \mathrm{C}$, com máxima de $34^{\circ} \mathrm{C}$ e mínima de $2^{\circ} \mathrm{C}$. No inverno o fenômeno das geadas é comum durante os dias mais frios. A época da estiagem ocorre no período de maio a setembro e o mês chuvoso costuma ser janeiro, com índice médio pluviométrico anual de $1.300 \mathrm{~mm}$, atingindo um total de chuvas superior a 10 vezes a do mês de julho (ONG MÍSTICOS CAMPOS, 2005).

Para realização deste estudo foram utilizados os seguintes materiais e equipamentos:

- Carta Hidrográfica de Bueno Brandão, escala de 1:75. 000 (IGA, 2001);

- Software SPRING, versão 4.3.3 (CÂMARA et al., 1996);

- GPS ETREX - GARMIN, versão 2.09;

- Formulário Cadastral para a entrevista com os bataticultores.

A metodologia proposta neste trabalho consistiu em cadastrar os bataticultores nas propriedades amostradas aleatoriamente na área de estudo e efetuar o registro espacial das áreas de plantio.
O levantamento cadastral das propriedades foi feito em janeiro de 2008. Neste período os agricultores que haviam plantado no ano anterior para a safra das águas, preparavam-se para a colheita. Deste modo, tornou-se possível encontrá-los em suas propriedades e entrevistá-los, quanto: às áreas de plantio, aos tipos e às dosagens de fertilizantes e agrotóxicos empregados, ao tipo de maquinário utilizado e averiguar se haviam feito a análise do solo, para verificar quais eram as necessidades reais de nutrientes ao solo.

No total foram cadastradas 30 propriedades, mas somente 18 amostras foram consideradas para o estudo, pois o cultivo da batata ocorria na mesma safra. Deste modo, todos estariam sujeitos ao mesmo tipo de ação de pragas e expostos às mesmas condições de pluviosidade e temperatura, utilizando-se de produtos agroquímicos e cuidados similares ao preparo da terra e plantio da cultura.

Em cada uma das áreas de cultivo cadastradas foi coletado um ponto com as coordenadas geográficas do local utilizando-se do GPS de navegação ETREX - GARMIN, a fim de identificar o local. Para a localização dos pontos levantados pelo GPS no mapa da sub-bacia, os dados foram importados para 
o software SPRING, versão 4.3.3 (CÂMARA et al., 1996). Concomitantemente, foi realizada a avaliação visual do local para averiguar se o plantio ocorria em áreas que deveriam ser destinadas à preservação permanente ou próximo delas.

\section{RESULTADOS E DISCUSSÃO}

Verificou-se junto aos bataticultores entrevistados que os agrotóxicos utilizados em mais de 50\% das lavouras cadastradas foram: Astro, Bravonil 500,
Curzate, Dithane PM, E Karate Zeon 50CS. Os ingredientes ativos destes agrotóxicos são, respectivamente: Clorpirifós, Clorotalonil, Cimoxanil+Mancozebe, Mancozebe e Lambda-cialotrina. Todos são enquadrados na classe ambiental perigosa ou muito perigosa, considerando-se as informações técnicas da Agência Nacional de Vigilância Sanitária (ANVISA, 2008) (Quadro 2).

Quadro 2: Principais agrotóxicos utilizados pelos bataticultores em Bueno Brandão, MG.

\begin{tabular}{|c|c|c|c|c|c|}
\hline Produto & Tipo & Ingrediente Ativo & Grupo Químico & Classe Toxicológica & $\begin{array}{c}\text { Classificação } \\
\text { Ambiental }\end{array}$ \\
\hline ASTRO & Inseticida & Clorpirifós & Organofosforado & $\begin{array}{c}\text { Medianamente } \\
\text { tóxico - III }\end{array}$ & $\begin{array}{c}\text { Muito perigoso } \\
- \text { II }\end{array}$ \\
\hline $\begin{array}{c}\text { BRAVONIL } \\
500\end{array}$ & Fungicida & Clorotalonil & Isoftalonitrila & $\begin{array}{c}\text { Extremamente } \\
\text { tóxico - I }\end{array}$ & $\begin{array}{c}\text { Muito perigoso } \\
- \text { II }\end{array}$ \\
\hline CURZATE BR & Fungicida & $\begin{array}{c}\text { Cimoxanil + man- } \\
\text { cozebe }\end{array}$ & $\begin{array}{c}\text { Acetamida + alquile- } \\
\text { nobis (ditiocarbamato) }\end{array}$ & $\begin{array}{c}\text { Medianamente } \\
\text { tóxico - III }\end{array}$ & Perigoso - III \\
\hline $\begin{array}{c}\text { DITHANE PM } \\
\text { KARATE } \\
\text { ZEON 50CS }\end{array}$ & $\begin{array}{c}\text { Acaricida - fun- } \\
\text { gicida }\end{array}$ & Mancozebe & $\begin{array}{c}\text { Alquilenobis (ditio- } \\
\text { carbamato) }\end{array}$ & $\begin{array}{c}\text { Medianamente } \\
\text { tóxico - III }\end{array}$ & $\begin{array}{c}\text { Muito perigoso } \\
- \text { II }\end{array}$ \\
\hline
\end{tabular}

Org. dos autores.

Em pesquisa realizada por Spadotto et al. (2001) foi verificado que a meia-vida destes ingredientes ativos, exceto do Mancozebe, é de 30 dias e que todos apresentam baixa mobilidade e pequeno risco de lixiviação no solo. No entanto, de acordo com Ferracini et al. (2001), a meia vida do Mancozebe é de 70 dias e o mesmo apresenta grande mobilidade no ambiente, sendo um contaminante em potencial das águas superficiais, devido ao transporte associado ao sedimento em suspensão.
Deve-se atentar ao fato de que as dosagens de aplicação relatadas pelos bataticultores foram majoritariamente superiores às recomendadas pela ANVISA (Tabela 2). 
Tabela 2: Dados cadastrais sobre 18 lavouras de batatas em Bueno Brandão, MG.

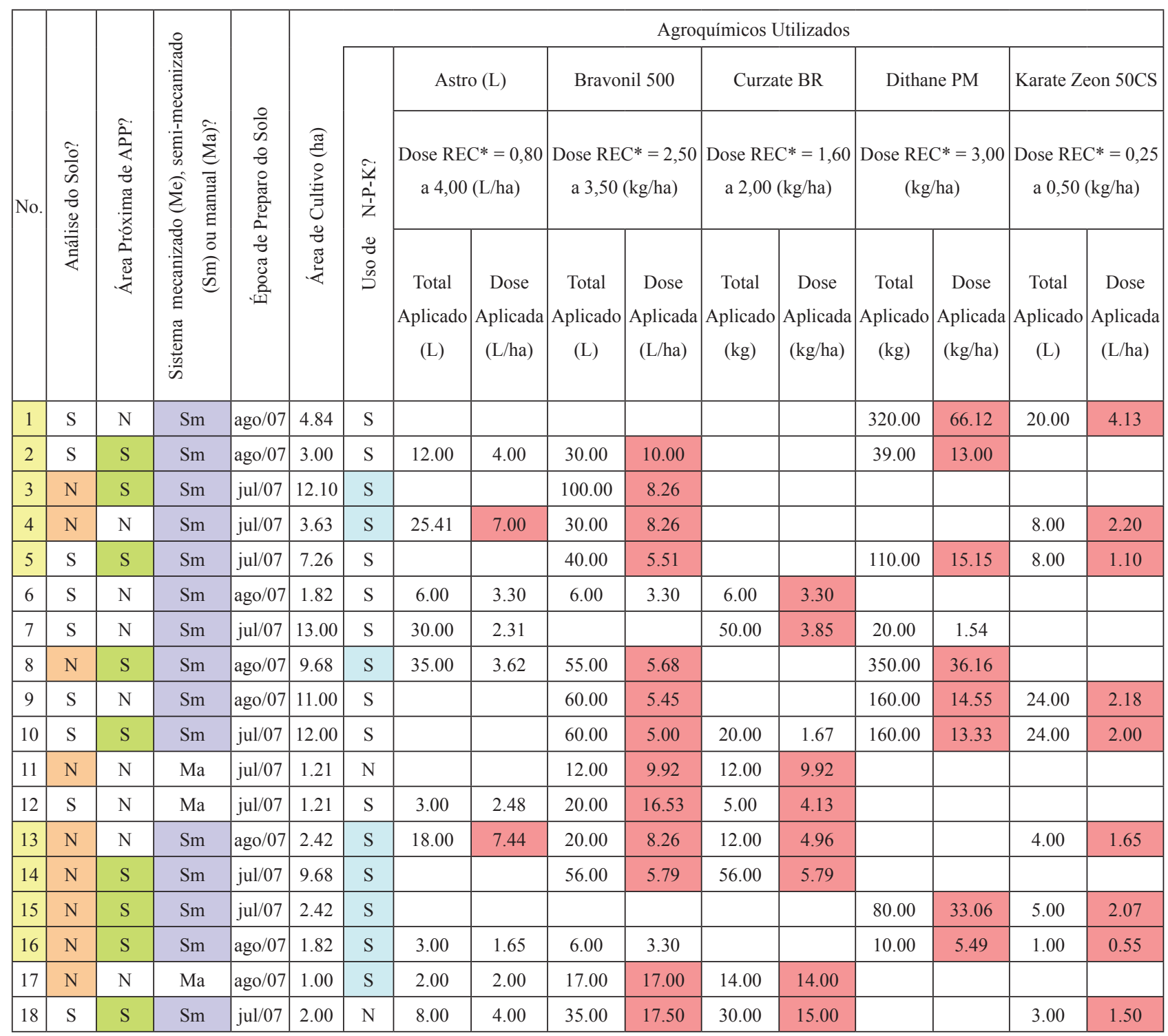

Obs: Dose $\mathrm{REC}^{*}=$ dosagem recomendada pela Agência de Vigilância Sanitária (ANVISA).

\section{LEGENDA:}

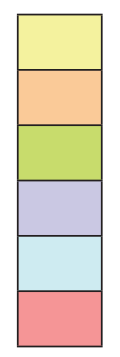

Áreas de plantio que fazem parte da sub-bacia do Rio das Antas;

Locais em que não foram realizadas análises do solo;

Áreas de plantio próximas de APP;

Emprego de sistema semi-mecanizado durante o plantio de batata;

Utilização de N-P-K sem a realização de análise do solo;

Aplicação de agrotóxicos com dosagem superior à recomendada pela ANVISA.

Elaboração dos autores. 
Outro fato importante verificado in loco, foi que as propriedades encontravam-se nas proximidades das APP, muitas vezes, sem mata ciliar de proteção. Assim sendo, os sedimentos que acumulavam estes agrotóxicos tenderiam a ser lançados e a contaminar os cursos d'água, por escoamento superficial, e as subterrâneas, por infiltração.

A partir do conjunto de informações levantadas, podem ser verificadas diversas características impactantes predominantes no sistema agrícola da região de estudo (Figura 2), entre elas:

- cerca de $70 \%$ das áreas de plantio cadastradas na sub-bacia do Rio das Antas, o cultivo da batata ocorre em regiões próximas de APP;

- dosagem superior ao recomendado pela ANVISA de quase todos os agrotóxicos na maioria das propriedades (mesmo para o caso do Curzate BR, onde todos que o utilizam, o fazem acima da dosagem recomendada na área de estudo), exceto para o produto Astro;

- aplicação de N-P-K sem análise prévia do solo em cerca de $70 \%$ das propriedades;

- falta de análise do solo em aproximadamente $70 \%$ das áreas de plantio;

- sistema semi-mecanizado de preparo do solo ou plantio em todas as propriedades cadastradas da sub-bacia, mesmo em locais com declividade superior a $20 \%$, que conforme Vieira (1988) são inadequados para este tipo de sistema.

Figura 2: Gráfico do percentual das áreas de bataticultura em função do modelo aplicado durante o plantio na sub-bacia do Rio das Antas, em Bueno Brandão, MG.

Dosagem de aplicação de KARATE ZEON 50CS acima da recomendada pela ANVISA Dosagem de aplicação de DITHANE PM acima da recomendada pela ANVISA Dosagem de aplicação de CURZATE BR acima da recomendada pela ANVISA Dosagem de aplicação de BRAVONII 500 acima da recomendada pela ANVISA Dosagem de aplicação de ASTRO acima da recomendada pela ANVISA Aplicação de N-P-K sem análise de solo Sistema semi-mecanizado de plantio Proximidade da área de plantio de batata de uma APP Falta de realização de análise de solo

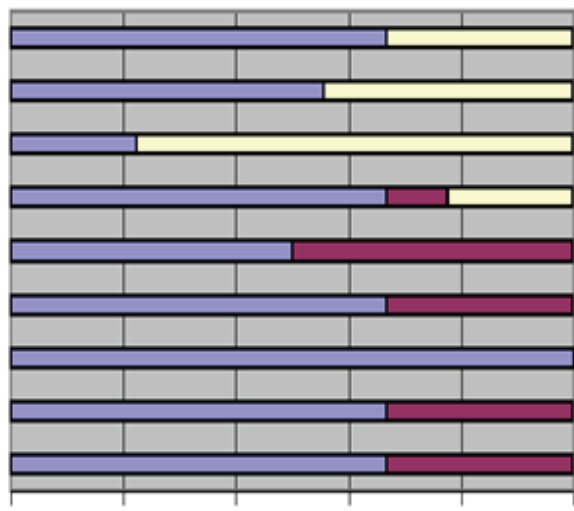
$0 \% \quad 20 \% \quad 40 \% \quad 60 \% \quad 80 \% \quad 100 \%$

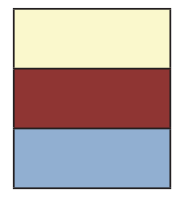

Produto não utilizado;

Caso negativo;

Caso afirmativo.

Org. dos autores.

Segundo Brigante et al. (2003a) na região próxima à sub-bacia do Rio das Antas, o sistema de plantio adotado pelos produtores tem sido inadequado, tanto no que se refere ao uso intensivo de agroquímicos, quanto ao plantio em locais de alta declividade, próximos ou inseridos em APP. Este fato foi claramente observado a partir dos dados levantados neste estudo.

\section{CONSIDERAÇÕES FINAIS}

As informações levantadas sobre os agroquímicos utilizados confirmaram a hipótese da pesquisa, que o uso dos mesmos é intensivo e de modo inadequado, pois além de utilizar dosagens de agrotóxicos superiores às recomendadas pela ANVISA, a maioria 
dos agricultores aplica N-P-K sem a realização de análise do solo preliminar, favorecendo o uso indiscriminado dos fertilizantes.

Também foi constatado que o sistema de plantio atual da região é inadequado, pois é do tipo semi-mecanizado, utilizando de equipamentos agrícolas como o trator e o arado fixo, em regiões íngremes de alta susceptibilidade à erosão laminar, e favorecendo a degradação hídrica das águas superficiais;

A verificação in loco da proximidade das áreas de plantio das APP foi importante, pois foi detectado que tais áreas encontram-se descobertas de vegetação, e mesmo com o plantio legalmente fora das mesmas, através do escoamento superficial nos locais de altas declividades, os produtos são direcionados sem obstáculos, ou seja, sem a interceptação de mata ciliar, para os cursos d'água.

Os resultados obtidos podem servir de subsídio para a realização de futuras pesquisas que avaliam o impacto ambiental na região. No entanto, algumas sugestões podem ser consideradas para facilitar ou melhorar a qualidades de tais estudos, entre elas:

- levantar dados a respeito da venda de agrotóxicos com receita agronômica comercializados no local e comparar as dosagens de aplicação dos mesmos com as que são regidas pela legislação em vigor;

- promover reuniões com os agricultores para explicar os motivos pelos quais as informações questionadas nos formulários são importantes para o desenvolvimento do estudo;

- levantar dados sobre o tipo de disposição de resíduos oriundos de embalagens de agrotóxicos, pois se lançados nos cursos d'água ou depositados em locais inadequados, também podem contribuir diretamente com a degradação hídrica de águas superficiais e subterrâneas;

- propiciar incentivos aos produtores para conservarem ou recuperarem a vegetação em áreas de preservação permanente.

\section{REFERÊNCIAS}

ANVISA (Agencia Nacional de Vigilância Sanitária). SIA - Sistema de Informações sobre Agrotóxicos. Disponível em <http://www4.anvisa.gov.br/agrosia/asp/ default.asp>. Acesso em: 08 jan. 2008.

ALABURDA, J.; NISHIHARA, L. Presença de compostos de Nitrogênio em águas de poços. Revista de Saúde Pública, São Paulo, v. 32, n. 2, p.160-165 abr. 1998.

BERTON, R.S. Impacto dos fertilizantes e corretivos. In: SIMPÓSIO SOBRE IMPACTO AMBIENTAL POR USO AGRÍCOLA DO SOLO, 1., 1994, Campinas. Anais... Campinas, 1994. p. 73-84.

BRASIL. Lei Federal $n^{\circ}$ 7.802, de 11 de julho de 1989. Dispõe sobre a pesquisa, a experimentação, a produção, a embalagem e rotulagem, o transporte, o armazenamento, a comercialização, a propaganda comercial, a utilização, a importação, a exportação, o destino final dos resíduos e embalagens, o registro, a classificação, o controle, a inspeção e a fiscalização de agrotóxicos, seus componentes e afins, e dá outras providências. Disponível em: $<$ http://www.planalto.gov. br/ccivil/LEIS/L7802.htm>, acesso em 11 fev. 2008.

BRIGANTE, J.; ESPÍNDOLA, E.L.G. POVINELLI, J.; NOGUEIRA, A. M. Caracterização Física, Química e Biológica da água do Rio Mogi-Guaçu. In: BRIGANTE, J.; ESPÍNDOLA, E.L.G. (Ed.). Limonologia fluvial - um estudo no Rio Mogi-Guaçu. São Carlos: RiMa, 2003a. p.55-76.

BRIGANTE, J.; MERENGO, M. C.; ESPÍNDOLA, E.L.G.; VIEIRA, E. M. Praguicidas nos Sedimentos do Rio Mogi-Guaçu. In: BRIGANTE, J.; ESPÍNDOLA, E.L.G. (Ed.). Limonologia fluvial - um estudo no Rio Mogi-Guaçu. São Carlos: RiMa, 2003b. p.121-128.

BRUNS, G. B. Gestão de Impactos Sociais. Jornal Diário: Ambiente Brasil. 20 mar. 2008. Caderno: Gestão, Artigos. Disponível em: $<$ http://www.ambientebrasil.com.br/composer.php3?base=./gestao/index. html\&conteudo=./gestao/artigos/gestao_impactos. html>, acesso em: 20 mar. 2008.

CÂMARA, G.; SOUZA, R.C.M.; FREITAS, U.M.; GARRIDO, J.; LI, F. M.; SPRING: Integrating Remote Sensing and GIS by Object-Oriented Data 
Modelling. Computer and Graphics, v.20, n. 3, p. 395-403, 1996.

CARRARO, G. Agrotóxico e Meio Ambiente: Uma Proposta de Ensino de Ciências e de Química. Porto Alegre: UFRS - Instituto de Química, Área de Educação Química, 1997. 90p.

CENTRO DE INTELIGÊNCIA DA BATATA - CIB. Dados sobre a batata. 2008.Disponível em: $<\mathrm{http}$ :/ www.cib.agro.com.br>. Acesso em: 22 jan. 2008.

COSTA, A. Manejo da fertilidade do solo no sistema plantio direto. In: MORAES, M. H.; MÜLLER, M. M. L.; FOLONI, J. S. S. Qualidade física do solo: métodos de estudo - sistemas de preparo e manejo do solo. Jaboticabal: Fundação de Estudos e Pesquisas em Agronomia, Medicina Veterinária e Zootécnica-FUNEP, 2001. p.198-225.

FERRACINI, V. L.; PESSOA, M. C. Y. P.; SILVA, A. S.; SPADOTTO, C. A. Análise de Risco de Contaminação das Águas Subterrâneas e Superficiais da Região de Petrolina (PE) e Juazeiro (BA). Pesticidas: Revista de Ecotoxicologia e Meio Ambiente. Curitiba: UFPR, v. 11, p.1-16, jan./dez. 2001.

FILGUEIRA, F. A. R. Práticas Culturais Adequadas em Bataticultura. Informe Agropecuário, Belo Horizonte: EPAMIG, v.20, n.197, p.34-41, mar./abr. 1999.

INSTITUTO BRASILEIRO DE GEOGRAFIA E ESTATÍSTICA - IBGE. Sistema IBGE de recuperação automática - SIDRA. Disponível em: $<$ http://www.sidra.ibge.gov.br/bda/acervo/acervo2. asp? $\mathrm{e}=\mathrm{v} \& \mathrm{p}=\mathrm{CA} \& \mathrm{z}=\mathrm{t} \& \mathrm{o}=11>$. Acesso em: 02. nov. 2012.

INSTITUTO DE GEOCIÊNCIAS APLICADAS (IGA). Carta Hidrográfica de Bueno Brandão. Belo Horizonte, 2001.

KATO, R. Batata ganha Ano Internacional e destaque no combate à fome. USP Notícias, São Paulo, 18 jan. 2008. Caderno: Economia \& Política. Disponível em: <http://www.noticias.usp.br/acontece/obterNo ticia codntc $=19004 \&$ codnucjrn $=1>$.Acesso em: 22 jan. 2008.

LIMA, M. A.; VALARINI, P. Desenvolvimento de modelo conceitual metodológico de análise de impacto ambiental em áreas de agricultura irrigada. In: CONGRESSO NACIONAL DE IRRIGAÇÃO E DRENAGEM - CONRID, 1996, Campinas, SP. Anais... Campinas: ABID, 1996. p.427-446.

LUDOVICE, M. T. F. Influência de faixa filtro de Brachiaria decumbens na retenção de atrazina, nutrientes e sedimentos em escoamento superficial. 2003. $183 \mathrm{f}$. Tese (Doutorado em Engenharia Agrícola) - Faculdade de Engenharia Agrícola, Universidade Estadual de Campinas, Campinas, 2003.

MELO, P. C. T. Ano da Batata. Associação Brasileira de Horticultura, 2008. Biblioteca. Disponível em: <http://www.abhorticultura/biblioteca/default. asp?id=6621>. Acesso em: 02 jul. 2008.

MESQUITA, H. A.; PAULA, M. B.; ALVARENGA, M. I. N.; REGINA, S. M. A Cultura da Batata e a Preservação Ambiental. Informe Agropecuário. Belo Horizonte: EPAMIG, v.20, n.197, p.20-23, mar./abr. 1999.

MÍSTICOS CAMPOS (Organização Não Governamental Místicos Campos). Água e seus reflexos na saúde e na economia de Bueno Brandão. Workshop. Inconfidentes: EAFI, 2005.

PERES, F.; MOREIRA, J. C. Saúde e ambiente em sua relação com o consumo de agrotóxicos em um pólo agrícola do Estado do Rio de Janeiro, Brasil. Caderno de Saúde Pública, Rio de Janeiro, n. 23, Sup 4:S612-S621, 2007.

PORTAL FARMÁCIA. Definição e Classificação dos Agrotóxicos. 2008. Disponível em: <http://www. portalfarmacia.com.br/farmacia/principal/conteudo. asp?id=359> . Acesso em 11 fev. 2008.

ROCHA, D. C. C. Minas consolida liderança na produção de batata. Ambiente em Foco, Viçosa, 
13 set. 2007. Categoria: Agricultura, Cultura. Disponível em: <http://www.ambienteemfoco.com. $\mathrm{br} / ? \mathrm{~m}=20070913$ \&paged=2>, acesso em: 10 jan. 2008

SILVA, A. B. Entrevista concedida à Vassiliki Terezinha Galvão Boulomytis. Bueno Brandão, MG. 05 jan. 2008.

SPADOTTO, C. A.; FILIZOLA, H.; GOMES, M. A. F. Avaliação do Potencial de Lixiviação de Pesticidas em Latossolo da Região de Guaíra, Sp. Pesticidas: Revista de Ecotoxicologia e Meio Ambiente. Curitiba: UFPR, v. 11, p.127-136, jan./dez. 2001.

VIEIRA, L. S. Manual da ciência do solo: com ênfase aos Solos Tropicais. 2. ed. São Paulo: Agronômica Ceres LTDA. 1988. 464p.
YOST, R.S.; KAMPRATH, E.J.; NADERMAN, G.C.;LOBATO, E. Residual effects of phosphorus applications on a high phosphorus adsorbing oxisol of Central Brazil. Soil Science Society of America Proceedings, Madison, v.45, n.3, p.540-543, 1981.

YOUNG, C. E. F. Competitividade e Tecnologias Limpas. Jornal Diário: Ambiente Brasil. 20 mar. 2008. Caderno: Gestão (Artigos). Disponível em: <http:// www.ambientebrasil.com.br/composer.php3?base $=. /$ gestao/index.html\&conteudo=./gestao/artigos/teclimpa.html>, acesso em 20 mar. 2008.

\section{AGRADECIMENTOS}

O trabalho foi realizado com auxílio financeiro da CAPES. 